\title{
Increased UV radiation due to polar ozone chemical depletion and vortex occurrences at Southern Sub-polar Latitudes in the period [1997-2005]
}

\author{
A. F. Pazmiño ${ }^{1,2}$, S. Godin-Beekmann ${ }^{1}$, E. A. Luccini ${ }^{3,4}$, R. D. Piacentini ${ }^{3,5}$, E. J. Quel ${ }^{6}$, and A. Hauchecorne ${ }^{2}$ \\ ${ }^{1}$ UPMC Univ. Paris 06, UMR 7620, Service d'Aéronomie, F-75005, Paris, France; CNRS, UMR 7620, Service d'Aéronomie, \\ F-75005, Paris, France \\ ${ }^{2}$ Université Versailles St-Quentin, CNRS, UPMC, Service d'Aéronomie, Route Forestière de Verrières, 91370 \\ Verrières-le-Buisson, France \\ ${ }^{3}$ Instituto de Física Rosario (CONICET - Universidad Nacional de Rosario), Rosario, Argentina \\ ${ }^{4}$ Facultad de Química e Ingeniería "Fray Rogelio Bacon", Universidad Católica Argentina, Rosario, Argentina \\ ${ }^{5}$ Facultad de Ciencias Exactas, Ingeniería y Agrimensura, Universidad Nacional de Rosario, Rosario, Argentina \\ ${ }^{6}$ CEILAP (CITEFA-CONICET), Villa Martelli, Argentina
}

Received: 25 January 2008 - Published in Atmos. Chem. Phys. Discuss.: 4 April 2008

Revised: 1 August 2008 - Accepted: 4 August 2008 - Published: 8 September 2008

\begin{abstract}
.
The variability of total ozone and UV radiation from Total Ozone Mapping Spectrometer (TOMS) measurements is analyzed as a function of polar vortex occurrences over the southern subpolar regions during the 1997-2005 period. The analysis of vortex occurrences showed high interannual variability in the $40^{\circ} \mathrm{S}-60^{\circ} \mathrm{S}$ latitude band with a longitudinal asymmetry showing the largest frequencies over the $90^{\circ} \mathrm{W}-$ $90^{\circ} \mathrm{E}$ region. The impact of vortex occurrences on UV radiation and ozone in clear sky conditions was determined from the comparison between the measurements inside the vortex and a climatology obtained from data outside the vortex over the studied period. Clear sky conditions were determined from TOMS reflectivity data. For measurements outside the vortex, clear sky conditions were selected for reflectivity values lower than $7.5 \%$, while for measurements inside the vortex, a relaxed threshold was determined from statistically similar UV values as a function of reflectivity. UV changes and ozone differences from the climatology were analyzed in the $40^{\circ} \mathrm{S}-50^{\circ} \mathrm{S}$ and $50^{\circ} \mathrm{S}-60^{\circ} \mathrm{S}$ latitude bands during the spring period (September to November). The largest UV increases and ozone decreases, reaching $\sim 200 \%$ and $\sim 65 \%$,
\end{abstract}

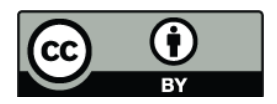

Correspondence to: Andrea Pazmino (andrea.pazmino@aero.jussieu.fr) respectively, were found in the $50^{\circ} \mathrm{S}-60^{\circ} \mathrm{S}$ latitude band in September and October. The heterogeneous ozone loss during vortex occurrences was estimated using a chemical transport model. The largest impact of vortex occurrences was found in October with mean UV increase, total ozone decrease and accumulated ozone loss in the $350-650 \mathrm{~K}$ range of, respectively, $47 \%, 30 \%$ and $57 \%$. The region close to South America is the most affected by the Antarctic ozone depletion due to the combined effect of large number of vortex occurrences, lower cloud cover and large ozone decrease. This region would be the most vulnerable in case of cloud cover decrease, due to more frequent occurrence of ozone poor air masses during austral spring.

\section{Introduction}

In the most recent years, the ozone hole area has shown a larger variability than previously observed (see for example Fig. 1 in Newman et al., 2006). The year 2001 was characterized by a relatively large ozone hole that remained up to mid-December. Then in the year 2002, a remarkably high planetary wave activity took place in the Southern Hemisphere, which contrasted with previous years (Allen et al., 2003). This activity brought about, at the end of September,

Published by Copernicus Publications on behalf of the European Geosciences Union. 
the first stratospheric major warming ever observed in the Southern Hemisphere (Hoppel et al., 2003; Randall et al., 2005; Scaife et al., 2005). In the middle and high stratosphere, the air masses rich in ozone from mid-latitudes were transported to the Polar Regions (Kondragunta et al., 2005). In that altitude range, the ozone hole divided in two lobes. The consequence of the 2002 major warming was a significant decrease of the surface of the ozone hole and its early disappearance. In 2003, a typical ozone hole was observed within a very large area in September. Then, in 2004, the ozone hole area was rather small as compared to the other years (except 2002) and the year 2005 was again characterized by a big ozone hole. After 2002, a saw-tooth pattern of relatively small ozone hole in even years and mostly larger in odd years was observed (WMO, 2006). However, the year 2006 has been characterized by one of the largest ozone hole, comparable to those observed in 2000 and 2003.

It was shown by different works (Kirchoff et al., 1997; Pérez et al., 2000; Cede et al., 2002; Pazmiño et al., 2005), that the subpolar regions of the Southern Hemisphere were affected by short periods of weak total ozone values directly linked to overpasses of the ozone hole. During these episodes, the subpolar regions experience a pronounced ozone reduction with generally an enhancement of UV-B radiation, depending on cloud cover conditions. Other studies have shown that the populated regions of the South America Southern tip are a preferential area for vortex occurrences in the spring period (Compagnucci et al., 2001; Huth and Canziani, 2003). In a previous work (Pazmiño et al., 2005), we have analyzed the local increase of erythemal dose linked to vortex occurrences at mid-latitude and polar stations of the Southern Hemisphere. Episodic daily erythemal dose increases larger than twice the climatological value were found at the Argentinean town of Ushuaia $\left(54.9^{\circ} \mathrm{S}, 68.3^{\circ} \mathrm{W}\right)$ linked to vortex occurrences over the station during the period 1997-2003. The average erythemal UV increase due to these events was evaluated to $68 \%$ over this period. Casiccia et al. (2003) have found episodic UV index increases larger than $100 \%$ over Punta Arenas $\left(53.1^{\circ} \mathrm{S}, 70.9^{\circ} \mathrm{W}\right)$ in Chile in October 2000 due to vortex overpasses.

In the present study, we analyzed the whole subpolar latitude region using total ozone and local noon erythemal UV irradiance (converted to UV index) of TOMS during the 1997-2005 period. The cloud cover conditions were taken into account using TOMS's reflectivity values. In addition, a high spatial resolution advection model coupled to an ozone chemistry parameterization (ATOLL-Advection Transport model with Ozone Linearization scheme at isentropic Levels) was used in order to link the UV increase to accumulated chemical ozone loss during each Antarctic winter and spring. The model was also used to detect the preferential regions of vortex displacements characterized by large chemical ozone loss but no significant UV enhancements as derived from TOMS measurements. The lack of UV sensitivity to significant ozone decreases in some regions is ex- plained by an important attenuation due to cloud cover. The regions with this combined effect of preferential vortex displacements and high cloud cover condition are more vulnerable to cloud cover decrease linked to climate change, as the stratospheric ozone layer slowly returns to pre-ozone hole conditions. Newman et al. (2006) showed that the unambiguous detection of ozone hole decrease due to decrease in ozone depleting substances (ODS) will probably not occur before 2020. This delay in the detection of ozone hole recovery is linked to the atmospheric variability in the southern polar stratosphere and the long life time of ODS in the stratosphere, especially in the Polar Regions.

This paper is organized as follows. Firstly, the data and methodology used to study the reduction in total ozone and enhancement in UV index linked to polar vortex occurrences are shown. Then, the ATOLL model used to simulate ozone loss partial columns is presented and validated. These simulations were used to link UV changes with chemical ozone loss. In the next section, the main features of vortex displacements over the Southern Hemisphere are analyzed for the whole period 1997-2005. Then the variation in total ozone and UV index linked to polar vortex occurrences are quantified over the sub-polar regions and mid-latitude regions $\left(40^{\circ} \mathrm{S}-60^{\circ} \mathrm{S}\right)$ using TOMS data. In a following section, the relationship between UV changes and chemical ozone loss is analyzed using partial ozone columns from ATOLL simulations. The potentiality of different regions to possible UV enhancement in a hypothetical scenario of cloud cover decrease is analyzed. Finally, the main results of the work are summarized and conclusions are presented.

\section{Impact of vortex occurrences on ozone and UV radiation}

\subsection{Data and methodology}

In order to quantify the occurrences of the vortex at mid-latitudes over the 1997-2005 period, the equivalent latitude (EL) at the potential temperature level $\theta=550 \mathrm{~K}$ is used. It is calculated from PV field simulated by the MIMOSA PV advection model (Hauchecorne et al., 2002). The EL at $550 \mathrm{~K}$ is computed at each elementary grid area $\left(1^{\circ} \times 1^{\circ}\right)$ of the PV field of the latitude band $30^{\circ} \mathrm{S}-$ $90^{\circ} \mathrm{S}$. The meteorological analyses from the European Centre for Medium-Range Forecasts (ECMWF) $1.125^{\circ} \times 1.125^{\circ}$ (T106 truncation) analyses are used for the PV calculation. Such a method was already used in previous studies for the discrimination of polar and non polar measurements performed at the edge of the vortex (Godin et al., 2001; Pazmiño et al., 2005). The EL is a modified PV variable enclosing the same area as the PV contour. In the quasi-conservative coordinate system (EL, $\theta$ ) firstly described by McIntyre and Palmer (1984), the EL of each elementary area is compared to the EL of the vortex edge for classification. The inner and 
outer vortex regions are determined from the maximum of the PV gradient weighted by the wind module, as a function of EL (Nash et al., 1996). The classification is performed between 1 April and 31 December of each year of the period. This period was chosen to evaluate specially the vortex evolution. The vortex is firstly developed in the upper stratosphere in March to April. Then since June the vortex is well developed at the different isentropic levels. It generally breaks up at the end of November, beginning December. Previous studies showed that the highest correlation between potential vorticity and total ozone values was obtained at $550 \mathrm{~K}$ isentropic level (Bodeker et al., 2002; Pazmiño et al., 2005).

To quantify the changes in UV linked to total ozone decrease in sub-polar regions due to vortex occurrences, total ozone columns (TOC) values from TOMS (V8) (e.g. Labow et al., 2004) and TOMS-retrieved erythemal UV irradiance at local noon (Krotkov et al., 2002) are used. The erythemal irradiance in $\mathrm{W} / \mathrm{m}^{2}$ is multiplied by $40 \mathrm{~m}^{2} / \mathrm{W}$ to express it in UV Index (UVI) units (WHO, 2002). After interpolating the TOMS TOC and UVI data on a $1^{\circ} \times 1^{\circ}$ grid, two groups of data were distinguished according to the vortex position over each elementary area of the grid. The first group corresponds to TOC and UVI values inside and in the inner edge of the vortex, as determined by the previously described classification and the second group to data outside the vortex. The data of the latter group are also used to calculate the reference climatology of daily UVI and TOC values over the studied period. In this way, the TOC and UVI changes due to vortex occurrences are characterized by the difference between the values inside the vortex and the corresponding value of the climatology for that day and location.

Since UV radiation at the surface is strongly influenced by cloud conditions (WMO, 2003), only the data obtained in clear sky conditions are considered for the calculation of the UVI climatology. The separation of cloudy and clear sky data is determined from TOMS reflectivity data. The latter data is calculated from the backscattered radiance at $360 \mathrm{~nm}$ wavelength which is independent of ozone. This reflected radiation is assumed to originate from the ground and the tops of clouds in TOMS's algorithm (McPeters et al., 1998). The cloudless scenes measured by TOMS for most land and ocean surfaces have been studied by Eck et al. (1987). A ceiling value of reflectivity of around 7-8\% was determined for clear sky condition (Eck et al., 1987; Herman and Celarier, 1997; Wang et al., 2000). This minimum reflectance technique is not adequate for regions covered by snow and ice. The reflectivity of snow and ice surface is quite high in the UV, preventing the distinction between cloudy and cloud-free regions covered by snow and ice. The regions southern of $60^{\circ} \mathrm{S}$ were therefore not considered in the analysis since the sea ice in the Southern Ocean around Antarctica presents an important extension with a maximum reaching $60^{\circ} \mathrm{S}$ in average in September (cf. Fig. 1 of Zwally et al., 2002). The study was focused on the $50^{\circ} \mathrm{S}-60^{\circ} \mathrm{S}$ latitude range since this region is frequently affected by vortex occurrences as will be shown in Sect. 3. Three months were analyzed: September, October and November when the maximum frequencies of vortex occurrences are observed. This period was chosen since it shows the more frequent vortex occurrences over sub-polar regions, with its consequent ozone depletion and UV changes.

The first step to calculate the UVI climatology is to compute the zonal mean daily value from July to November over the 1997-2005 from UVI data with corresponding reflectivity lower than $7.5 \%$. Then the UVI daily evolution is fitted by a third-order polynomial. This period was chosen to fit correctly the evolution of UV with the polynomial fit since not enough UV values outside of the vortex are available before July over the $50^{\circ} \mathrm{S}-60^{\circ} \mathrm{S}$ latitude band. The TOC outside vortex monthly climatology is computed with a resolution of $1^{\circ} \times 1^{\circ}$. A climatology varying with latitude and longitude was chosen in order to reflect TOC climatological changes as a function of longitude as noted in Malanca et al. (2005). A monthly average is performed in order to take into account the dependence of TOC with season and to avoid the weak number of situations outside of the vortex for the higher latitudes.

The percentage differences in UVI and TOC values ( $\triangle \mathrm{UVI}$ and $\triangle \mathrm{TOC}$, respectively) due to vortex occurrences over an elementary space $\left(1^{\circ} \times 1^{\circ}\right)$ are determined as described by Eq. (1) for UVI:

$\Delta \mathrm{UVI}(\lambda, \varphi, d)=100 \times \frac{\mathrm{UVI}(\lambda, \varphi, d)-\mathrm{UVI}_{\mathrm{cli}}(\lambda, d)}{\mathrm{UVI}_{\mathrm{cli}}(\lambda, d)}$

Where UVI represent the value inside the vortex at latitude $\lambda$, longitude $\varphi$ and day $d$ and $\mathrm{UVI}_{\mathrm{cli}}$ is the climatology value at latitude $\lambda$ and day $d$.

It was found in the study that for some latitude regions, the statistics of UVI and TOC measurements inside the vortex and for the specified criterion of clear sky condition was relatively poor. For example, only 58 elementary areas were found for clear sky condition over the whole September 1997-2005 period for the latitude band $50^{\circ} \mathrm{S}-60^{\circ} \mathrm{S}$, representing around $0.04 \%$ of the total number of elementary areas that were inside the vortex during that month and for all cloud cover conditions.

In order to improve the statistical results, a relaxed condition of the ceiling value of TOMS reflectivity was considered. To that aim, the change of UVI as a function of reflectivity was studied. Mean $\triangle \mathrm{UVI}$ values were calculated for each degree of latitude between $50^{\circ} \mathrm{S}$ and $60^{\circ} \mathrm{S}$ for September, October and November over the period 1997-2005. The mean values of $\Delta \mathrm{UVI}$ over the whole latitude band $\left(50^{\circ} \mathrm{S}-\right.$ $\left.60^{\circ} \mathrm{S}\right)$ together with the two standard error confidence interval $(2 \sigma)$ are shown in Fig. 1 for September, October and November as a function of reflectivity with a step of $5 \%$. As expected, the mean $\Delta U V I$ is the largest for lower reflectivity values for the three months. It becomes negative for reflectivity values larger than $40 \%$ in September and October and 

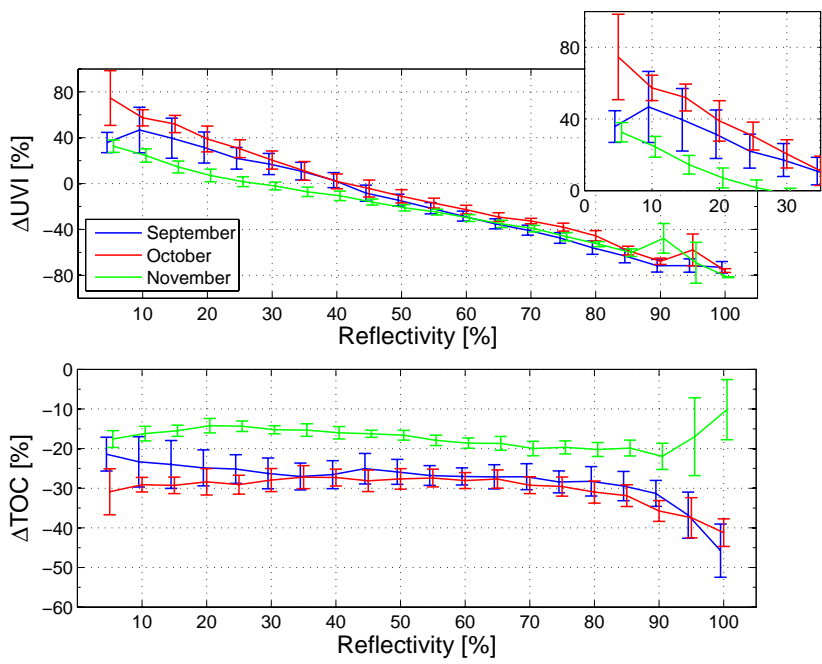

Fig. 1. Zonal $\triangle U V I$ (top panel) and $\triangle T O C$ (bottom panel) and the $2 \sigma$ Standard Error of the mean for September (blue curve), October (red curve) and November (green curve) for different reflectivity values (step of $5 \%$ in the $\pm 2.5 \%$ interval) in the $50^{\circ} \mathrm{S}-60^{\circ} \mathrm{S}$ latitude band. The small panel in the right upper part of the top figure shows a zoom of the data for small reflectivity values.

$30 \%$ for November. The mean $\Delta \mathrm{UVI}$ corresponding to reflectivity values lower than $10 \%$ vary from $50 \%$ in September, $75 \%$ in October and 35\% in November. For the highest reflectivity values, $\Delta \mathrm{UVI}$ can reach $-80 \%$. The mean $\Delta \mathrm{UVI}$ of September and October are comparable within $2 \sigma$ standard error confidence intervals and are generally larger than the mean $\triangle \mathrm{UVI}$ in November.

The relaxed criterion for the ceiling reflectivity threshold is obtained by comparing the mean $\Delta$ UVI values for different reflectivity values to the maximum mean $\Delta U V I$ at $2 \sigma$ standard error level. It can be seen in the top panel of Fig. 1 that the mean values associated to reflectivity larger than $27.5 \%$ in September, $22.5 \%$ in October and $12.5 \%$ in November are significantly different at $2 \sigma$ standard error level. These thresholds of reflectivity represent thus the quasi-clear sky condition of the studied period for the corresponding month. In these conditions, the number of elementary areas considered inside the vortex was increased from $0.04 \%$ to $9.2 \%$ in September, from $0.16 \%$ to $4.5 \%$ in October and from $0.13 \%$ to $1.1 \%$ in November. The mean $\triangle \mathrm{TOC}$ were also represented in Fig. 1 (bottom panel) together with the $2 \sigma$ standard error confidence interval. It varies weakly with the reflectivity as compared to $\Delta U V I$ variation. The mean $\triangle \mathrm{TOC}$ values are always negative for the three months. The monthly average of mean $\Delta \mathrm{TOC}$ is $-27.9 \pm 2.4 \%$ for September, $-30.2 \pm 1.7 \%$ for October and $-17.1 \pm 1.2 \%$ for November. In the latter month, the mean $\triangle \mathrm{TOC}$ values are significantly smaller in absolute value. Figure 1 shows a small decrease with reflectivity increase for September and
October that is not significant at $2 \sigma$ level compared to clear sky condition except for reflectivity values larger than $90 \%$. These high reflectivity values correspond to regions close to $60^{\circ} \mathrm{S}$, where indeed the largest ozone decreases are found in the $50^{\circ} \mathrm{S}-60^{\circ} \mathrm{S}$ latitude band.

A similar analysis was done for the $40^{\circ} \mathrm{S}-50^{\circ} \mathrm{S}$ latitude band. We found similar behavior but the UVI increases at low reflectivity values are weaker than those of the southern latitude band due to weaker total ozone decrease. The values of reflectivity criteria were restricted to $27.5 \%$ on September, $17.5 \%$ on October and $7.5 \%$ in November.

\subsection{Simulation of partial ozone column (POC) of ATOLL model}

\subsubsection{Model description}

The ATOLL model was developed to obtain a high resolution 4-D representation of the ozone hole with a simple parametrization of ozone chemistry over the period 19972005. ATOLL is a result of the coupling of the high resolution advection transport model Modèle Isentropique de transport Mesoechelle de l'Ozone Stratosphérique par Advection (MIMOSA, Hauchecorne et al., 2002) with the LINearized OZone (LINOZ, McLinden et al., 2000) chemistry parametrization for ozone homogeneous chemistry and to the MIDdle atmosphere RADiation scheme (MIDRAD, Shine, 1987) for vertical transport calculation using ozone in an interactive way. We have also established a heterogeneous ozone chemistry parametrization to take into account the important ozone depletion in the Polar Regions of the Southern Hemisphere.

Three ozone tracers are defined: one that it is not affected by chemistry and the two others affected by homogeneous and heterogeneous chemistry, respectively. The three tracers are advected by the ECMWF wind analyses.

In its present version, the ATOLL model uses 16 isentropic levels between 350 and $950 \mathrm{~K}$ and covers the latitude band $30^{\circ} \mathrm{S}-90^{\circ} \mathrm{S}$ with a horizontal resolution of $1^{\circ} \times 1^{\circ}$. This spatial resolution is sufficient to simulate large scale events such as vortex displacements towards mid-latitude regions of the Southern Hemisphere.

In order to simulate the ozone loss at high latitudes regions due to heterogeneous chemistry, the activation of air masses induced by polar stratospheric cloud (PSC) formation and the related ozone destruction in the presence of solar radiation were parameterized. A cold tracer (CT) was incorporated into ATOLL in order to detect the activated air masses after their exposure to PSC. The CT varies between 0 and 1 , corresponding, respectively, to not activated and completely activated air. The time scale chosen for the activation rate is $\tau_{a}=7 \mathrm{~h}$ and $\tau_{d}=10$ days for the deactivation rate in a similar way to the previous work of Hadjinicolaou and Pyle (2004). $\mathrm{CT}$ is determined by comparing once per hour the temperature in each grid point polewards of $40^{\circ} \mathrm{S}$ for each isentropic 
level with the temperature of formation of type I PSC or NAT $\left(T_{\mathrm{PSC}}\right)$. Activated [deactivated] air mass is considered when the temperature is lower [higher] than $T_{\mathrm{PSC}}$ and CT is then computed from Eqs. (2) and (3).

$$
\begin{aligned}
& \mathrm{CT}(\lambda, \varphi, \theta, t+d t)=1-(1-\mathrm{CT}(\lambda, \varphi, \theta, t)) \times e^{-d t / \tau_{a}} \\
& \mathrm{CT}(\lambda, \varphi, \theta, t+d t)=\mathrm{CT}(\lambda, \varphi, \theta, t) \times e^{-d t / \tau_{d}}
\end{aligned}
$$

Where $\operatorname{CT}(\lambda, \varphi, \theta, t+d t)$ is the cold tracer at latitude $\lambda$, longitude $\varphi$, isentropic level $\theta$ and time $t+d t$. The temporal resolution $d t$ of ATOLL is $1 \mathrm{~h}$.

$T_{\mathrm{PSC}}$ is calculated from the pressure at the corresponding grid point and the mixing ratio of $\mathrm{HNO}_{3}$ and $\mathrm{H}_{2} \mathrm{O}$ (Hanson and Mauersberger, 1988). A climatology resulting from average zonal measurements of Limb Infrared Monitor of the Stratosphere instrument (LIMS) (Gille and Russell, 1984) is used for the values of $\mathrm{HNO}_{3}$ and a value equal to $5 \mathrm{ppmv}$ for $\mathrm{H}_{2} \mathrm{O}$. The ozone depletion rate due to heterogeneous chemistry is estimated via an empirical method using the CTM model MIMOSA-CHIM (Marchand et al., 2005; Tripathi et al., 2006) simulations and ozonesonde observations at South Pole (SPO $\left.-89.9^{\circ} \mathrm{S}, 102^{\circ} \mathrm{E}\right)$ and McMurdo (MMU $\left.-77.8^{\circ} \mathrm{S}, 166.6^{\circ} \mathrm{E}\right)$ stations. We have calculated a percentage of ozone depletion per $24 \mathrm{~h}$ of sunlight $\left(p_{24}\right)$. This percentage is multiplied by the value of the cold tracer which indicates the degree of activation in the corresponding point of grid only if the Solar Zenith Angle (SZA) is lower than $95^{\circ}$. Hadjinicolaou and Pyle (2004) fixed $p_{24}$ at $5 \%$. In the case of ATOLL, $p_{24}$ is variable with time and altitude. The sum of the ozone loss rates of the four main catalytic cycles involving chlorine and bromine constituent $(\mathrm{Cl}-\mathrm{O}$ and $\mathrm{ClO}-$ $\mathrm{ClO}$ cycles and the cycle $\mathrm{BrO}-\mathrm{ClO}$ via $\mathrm{ClO}_{2}$ and via $\mathrm{BrCl}$ ) of MIMOSA-CHIM was used as a guide for the estimation of the $p_{24}$ parameter in ATOLL. Then, the $p_{24}$ values were adjusted for the cold winter 2001 and the disturbed winter 2002, from the comparison of model results with ozone sonde measurements at South Pole and McMurdo stations. These stations were selected because they are generally inside the vortex. The ozone depletion rate is applied at each time step of the model $(1 \mathrm{~h})$ if SZA $<95^{\circ}$. The effective ozone loss is thus modulated by the value of the cold tracer and the duration of sunlight, which determines for ATOLL the difference from one winter to the next. Note that a constant percentage of ozone loss from one year to the next is adequate for the studied period characterized by a weak variation in total chlorine and bromine content in the stratosphere (WMO, 2007).

\subsubsection{Validation of the model simulations with ozone sonde} measurements

The ozone tracer influenced by dynamical processes and homogeneous and heterogeneous chemistry is compared to ozone sondes measurements at different isentropic levels. As an example, Fig. 2 shows the ozone mixing ratio at $475 \mathrm{~K}$ for

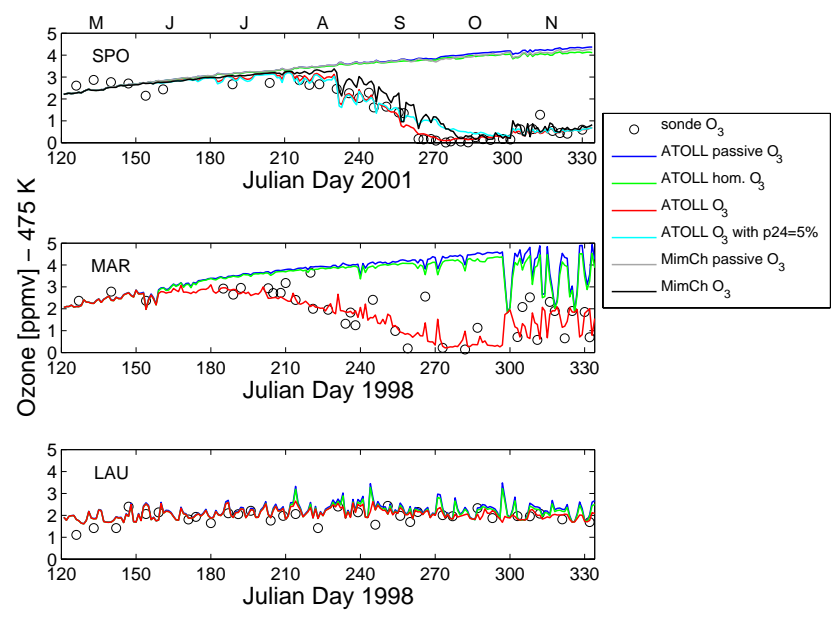

Fig. 2. Temporal evolution of the ozone mixing ratio at $475 \mathrm{~K}$ for South Pole (SPO) station in 2001 (top panel); and for Marambio (MAR) and Lauder (LAU) stations for the year 1998 (middle and bottom panels, respectively). The ozone values were retrieved from ozonesondes (circle) and ATOLL simulations with $p_{24}$ variable (red curve) (see its definition in Sect. 2.2.1). Passive ozone tracer (blue curve) and ozone due only to homogeneous chemistry (green curve) are also represented. The ozone and the passive ozone tracer of the CTM model MIMOSA-CHIM are shown only for the year 2001 as a cyan and black curves, respectively.

various stations. The three ozone tracers of ATOLL are represented in the figure: the passive ozone tracer, ozone linked to homogeneous chemistry and ozone associated to heterogeneous and homogeneous chemistry. Observations are shown by the markers. The upper panel displays the ozone simulations at South Pole (SPO), generally in the vortex core, for the winter-spring 2001. The ozone and passive ozone tracer simulations by the CTM model MIMOSA-CHIM are also represented in the figure (black and gray curves, respectively) for comparison with heterogeneous ozone tracer from ATOLL.

The ozone mixing ratio simulated by ATOLL and MIMOSA-CHIM presents negligible differences until the end of July. In August, the differences become more important and the simulation of ATOLL is in most of the cases in better agreement with the sondes measurements. The main differences between the simulations are noticeable in the months of September and October. ATOLL simulation reproduces the ozone decrease, the low values of ozone reached at the end of September and the beginning of October, in good agreement with observations. Moreover, it simulates correctly the low values of ozone persistent in October at the station. The MIMOSA-CHIM simulation reaches these low ozone values only by mid-October. Another parameterization for heterogeneous ozone loss rates was also used in ATOLL, ATOLL $5 \%$ (cyan curve) with $p_{24}$ equal to 5\% following the specification of Hadjinicolaou and Pyle (2004). 


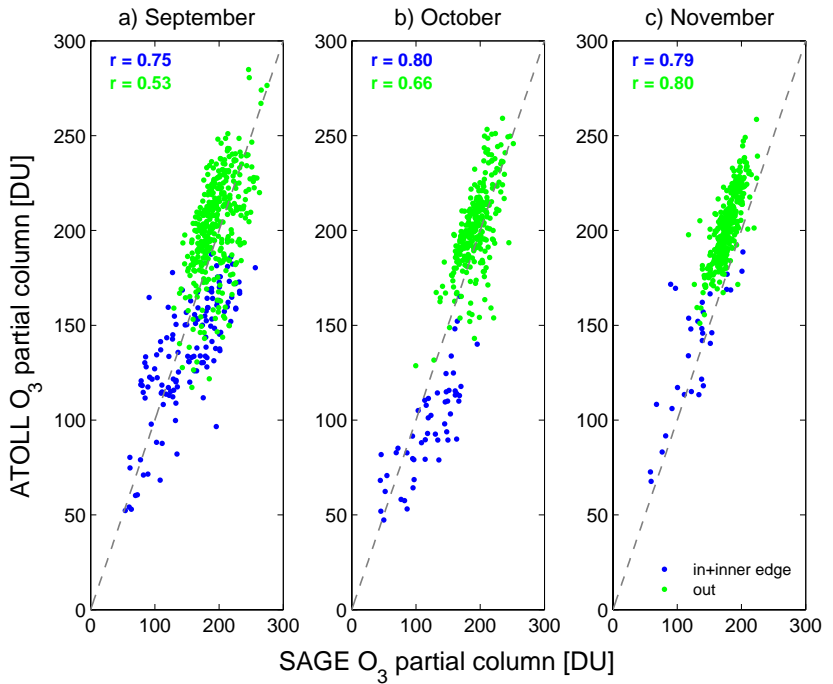

Fig. 3. Scatter plot of the $350-650 \mathrm{~K}$ partial ozone column of ATOLL and SAGE at the $40^{\circ} \mathrm{S}-60^{\circ} \mathrm{S}$ latitude band for: (a) September, (b) October and (c) November of the 1998-2004 period. POC amounts considered inside or in the inner edge of the vortex are represented by blue points and values associated to situations outside of the vortex with green points.

ATOLL $5 \%$ presents a good agreement until mid-September but the weakest ozone values are only reached at the end of October.

The comparison between ATOLL simulation and measurements performed at Marambio (MAR $-64.2^{\circ} \mathrm{S}, 56.7^{\circ} \mathrm{W}$ ), a station most of the time in the vortex edge (Pazmiño et al., 2005), and Lauder (LAU $\left.-45.04^{\circ} \mathrm{S}, 169.68^{\circ} \mathrm{E}\right)$, which were not used for the ATOLL formulation is represented in the Fig. 2 for the year 1998 (middle and bottom panel, respectively). ATOLL reproduces generally well the ozone evolution observed by ozonesondes at Marambio, which sample air masses inside and outside. The good agreement highlights the ability of the model to reproduce the complex behavior of ozone near the vortex edge. The mid-latitude station (LAU) presents differences between the passive ozone tracer and ozone due to homogeneous and heterogeneous chemistry from August. These differences are larger in October and November. During this period, the heterogeneous ozone tracer is in good agreement with sonde measurements. The ATOLL simulations shows that the ozone amounts at Lauder are much less affected by chemical ozone loss compared to e.g. Marambio, but the difference between ATOLL ozone (red curve) and ATOLL hom. ozone (green curve) is clearly visible on the figure. It reaches $0.5 \mathrm{ppm}$ or more at $475 \mathrm{~K}$. Since we are interested in the relationship between the partial ozone column (POC) and UV radiation, we have also compared the POC fields of ATOLL between 350 and $650 \mathrm{~K}$ isentropic levels to the corresponding POC of SAGE II (Mauldin et al., 1985) over the 1998-2004 period. SAGE II ceased operation after 2004. Figure 3 shows the comparison
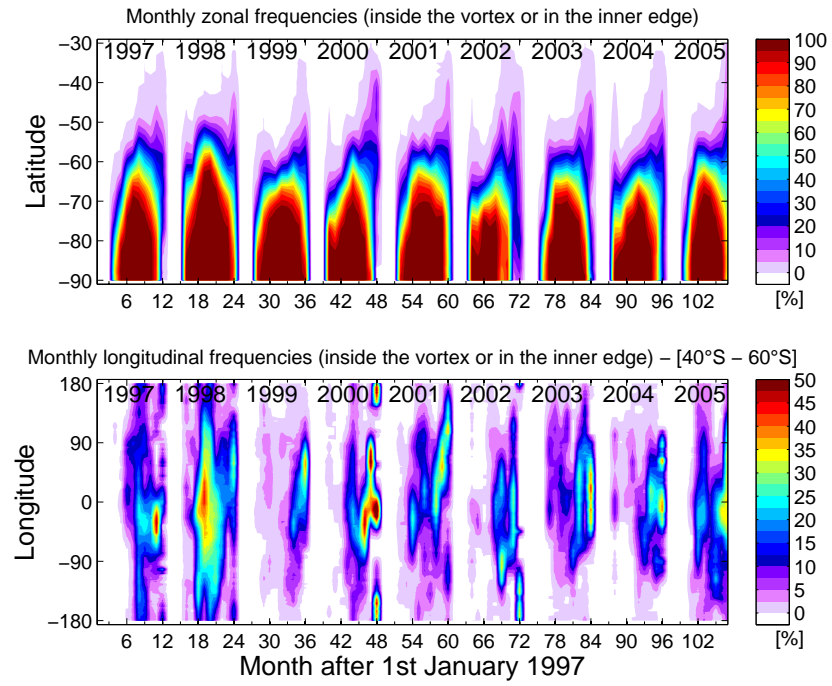

Fig. 4. Seasonal evolution of the average zonal and longitudinal frequency of the situations inside or in the inner edge of the vortex over the period 1997-2005. Scale of colors of 5\% and $2.5 \%$, respectively.

of simulated and observed POCs for the latitude band $40^{\circ} \mathrm{S}-$ $60^{\circ} \mathrm{S}$ in September, October and November. The situations inside the vortex are represented by blue points and the situations outside of the vortex by green ones. The mean relative POC differences between ATOLL and SAGE show an underestimation of the model in September of around 5.6\% for the situations inside the vortex and an overestimation of $4.4 \%$ for the situation outside the vortex. In October, the mean relative difference presents a larger mean underestimation of $14.9 \%$ for the situations inside the vortex. The situations outside the vortex show an overestimation comparable to that observed in September (5.1\% mean relative difference). In November, the model shows an overestimation of POC values for both types of situations of $\sim 13 \%$. The correlation of partial ozone values from ATOLL and SAGE is quite good for the situations inside the vortex with a correlation coefficient of 0.75 in September, 0.8 in October and 0.79 in November. For the situations outside of the vortex, the correlation is weaker especially in September: 0.53, 0.66 and 0.8, respectively. These various comparisons with ground-based and satellite measurements indicate that ATOLL reproduces in a satisfactory way the ozone partial column in the altitude range most affected by heterogeneous chemistry processes during the period of interest.

\section{Analysis of vortex occurrences over sub-polar regions}

The frequencies of vortex occurrences over the Southern Hemisphere as a function of latitude and longitude are analyzed using the methodology described in Sect. 2.1. Figure 4 shows the seasonal evolution of the monthly zonal frequencies of the situations inside the vortex over the period 
1997-2005 as a function of the latitude (upper panel). Frequencies larger than $90 \%$ are observed between $70^{\circ} \mathrm{S}$ and $90^{\circ} \mathrm{S}$ each year. The regions with frequencies larger than $90 \%$ extend northwards in June with a maximum extension generally in August and a southward regression around October. As an exception due to the major warming, the latitude range between $70^{\circ} \mathrm{S}$ and $90^{\circ} \mathrm{S}$ are characterized by frequencies lower than $90 \%$ between September and November in 2002. The annual evolution of frequencies larger than $70 \%$ is very similar from one year to the next with northernmost latitude of around $65^{\circ} \mathrm{S}$ generally reached in July and August. The years 1998 and 2002 stand out in these time series as the years when the polar vortex showed the, respectively, northernmost and southernmost extensions.

In the $50^{\circ} \mathrm{S}-60^{\circ} \mathrm{S}$ latitude range, vortex overpasses generally occur with frequencies lower than $50 \%$ except in 1998 when frequencies exceeding $70 \%$ were determined between $57^{\circ} \mathrm{S}$ and $60^{\circ} \mathrm{S}$ in August. The monthly frequencies of vortex overpasses in this latitude range present a larger interannual variability than at higher Southern latitudes. The weakest frequencies (below 5\%) reach their northernmost extension (generally around $35^{\circ} \mathrm{S}$ ) in November-December. In 2000, 2003 and 2005, these low frequencies reached $30^{\circ} \mathrm{S}$. In 2002 , vortex overpasses could be detected down to $30^{\circ} \mathrm{S}$ already in September and up to October. Note that all the frequencies displayed in Fig. 4 correspond to vortex occurrences before its breakup. The breakup of the vortex is determined when the maximum wind speed calculated along Ertel's PV isolines at $450 \mathrm{~K}$ isentropic level falls below $\sim 15.2 \mathrm{~m} / \mathrm{s}$ (Nash et al., 1996).

In order to study the asymmetry of the displacement of the austral vortex in the subpolar regions previously mentioned, the monthly longitudinal frequency of the situations inside the vortex for the sub-polar latitudes region are computed over the 1997-2005 period. The bottom panel of Fig. 4 displays the monthly longitudinal frequency for the $40^{\circ} \mathrm{S}-$ $60^{\circ} \mathrm{S}$ latitude band. It shows that the highest frequencies (approximately $35 \%$ ) in this latitude range are observed between $90^{\circ} \mathrm{O}$ and $90^{\circ} \mathrm{E}$. In this longitude range, the frequencies are generally lower than $25 \%$ until July, except in 1998 when higher values were reached. In September and October, the months when the vortex starts to be strongly deformed by planetary wave activity, the maximum frequencies vary between $30 \%$ and $50 \%$ at these longitudes. Other studies have analyzed the preferred regions of vortex displacements. The work of Moustaoui et al. (2003) has shown that regions over South America are preferred for wave breaking linked to the behavior of quasi- stationary wave 1 using a mean relative deviation between reconstructed PV from high resolution simulation and PV obtained from reanalysis. The waves induce upward displacements that produce polar-vortex-edge dilatation over those regions. Ajtic et al. (2004) have discussed where the Antarctic ozone depletion has the largest impact in the southern mid-latitude regions during the dilution of the ozone hole. They have shown that the impact is most
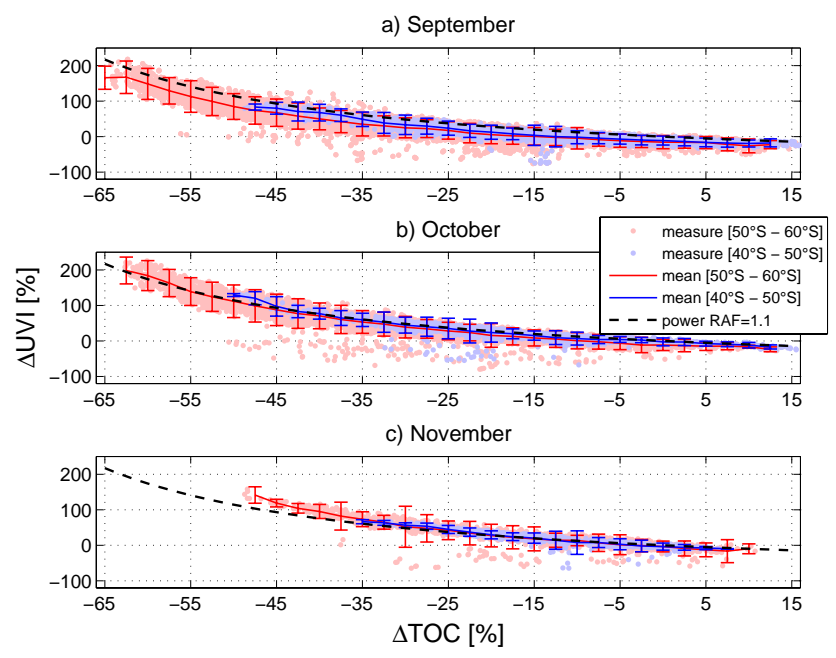

Fig. 5. Variation of relative UVI changes $(\Delta U V I)$ as a function of relative ozone differences $(\Delta \mathrm{TOC})$ on September (a), October (b) and November (c) for $50^{\circ} \mathrm{S}-60^{\circ} \mathrm{S}$ and $40^{\circ} \mathrm{S}-50^{\circ} \mathrm{S}$ latitude bands. Only quasi-clear sky conditions are considered. A moving average fit and the $2 \sigma$ standard deviation is represented with bold lines for the two latitudes bands. The RAF power rule is also represented by black dash lines.

pronounced in the regions encompassing South America and Africa (see Table 2 of Ajtic et al. for 15 October-14 November period).

\section{Variation of ozone and UV radiation over subpolar regions linked to vortex overpasses}

In order to analyze the relationship between local increases in UV and Antarctic vortex occurrences with low total ozone values, the UVI and TOC data from TOMS Version 8 were compared following the methodology described in Sect. 2.1 for the latitude band $50^{\circ} \mathrm{S}-60^{\circ} \mathrm{S}$. The latitude band $40^{\circ} \mathrm{S}-$ $50^{\circ} \mathrm{S}$ was also considered although it is characterized by much lower vortex occurrence frequencies: on the order of $2.3 \%$ in average as compared to $18.6 \%$ in average for the former latitude band as shown in Fig. 4. Figure 5 displays the variation of relative UVI changes ( $\triangle$ UVI) in September (a), October (b) and November (c) as a function of relative ozone differences ( $\triangle \mathrm{TOC}$ ) for both latitude bands. A moving average fit was applied to data at each $2.5 \% \Delta \mathrm{TOC}$ step, in a $\triangle \mathrm{TOC}$ interval of $\pm 1.25 \%$. The mean values and $2 \sigma$ standard deviation of $\Delta \mathrm{UVI}$ are represented with bold lines in Fig. 5a, b and c. The relationship between UV change and TOC differences shown in the figure are quite similar to that reported by UNEP (1998) where the dependence of erythemal ultraviolet radiation at the Earth's on atmospheric ozone was illustrated at various locations. This relationship is very similar within $2 \sigma$ standard deviation interval to a model prediction with a power rule using $\mathrm{RAF}=1.1$ (Madronich et al., 1998) described in the UNEP report that it is also represented in Fig. 5 (black lines). This is specially 
highlighted in October and November. Outlier values represent a negligible contribution to the mean $\Delta U V I$ values as seen by comparing the median and mean values for the three months.

The three months present similar UVI increases as a function of TOC changes as shown by the fitting bold lines in Fig. 5. Some differences are yet observed due to the different criteria for quasi-clear sky conditions. But these differences are negligible at $2 \sigma$ standard deviation level. Given that snow-covered surface over the southernmost region of South-America is still frequent during spring, and the fact that TOMS algorithm overestimates the actual cloud cover in cases of high reflectivity (e.g. Herman et al., 1999), it is possible that some clear-sky days over the continent were wrongly missed in our analysis. Nevertheless, the number of such data should be very small, as on average less than $5 \%$ of the time the sky has less than $10 \%$ cloud cover along this region during September, October and November, and the average surface UV albedo is lower than $40 \%$ (Luccini et al., 2006).

In September and October, large UVI increase between once and two times the climatological values are found for an ozone decrease of $50-65 \%$ between $50^{\circ} \mathrm{S}$ and $60^{\circ} \mathrm{S}$ (red points in Fig. 5). In the northernmost latitude band (blue points), maximum UV increases of $80 \%$ for September and $130 \%$ for October are observed for ozone decreases of $45 \%$ and $50 \%$, respectively. In November, $\Delta$ UVI can reach values as high as $70 \%$ for the northernmost latitude band and $140 \%$ for the southernmost one, associated with ozone decreases larger than $35 \%$ and $45 \%$, respectively. From data of Fig. 5, we calculated the radiation amplification factor (RAF) for each month following its definition $d(\operatorname{lnUVI})=-\mathrm{RAF}^{*} d(\operatorname{lnTOC})$ (Madronich et al., 1998). Model results show that the RAF depends on the SZA (Micheletti et al., 2003). However, due to the variability in the experimental conditions (change of the noon SZA within the month, not all points correspond to absolute clear-sky conditions, large differences between the ozone vertical profile inside and outside the vortex, etc.), the determined RAFs are statistically undistinguishable (within $2 \sigma$ ) from the theoretical reference value of $\mathrm{RAF}=1.1$ (Madronich et al., 1998) that it is also represented in Fig. 5 (black lines), and also the SZA dependence remains unobservable.

We then decided to focus our study of the impact of vortex occurrences on UV radiation at the $50^{\circ} \mathrm{S}-60^{\circ} \mathrm{S}$ latitude band, due to the rapid decrease of the number of vortex occurrences with high UV increases at the $40^{\circ} \mathrm{S}-50^{\circ} \mathrm{S}$ latitude band (see Fig. 5). In September and November UV increases do not reach $100 \%$ and in October, UV increase larger than $100 \%$ are found for only a few number of points.

\section{Chemical ozone loss associated to vortex occurrences}

In order to evaluate the chemical ozone loss over the $50^{\circ} \mathrm{S}-$ $60^{\circ} \mathrm{S}$ latitude band linked to vortex occurrences and to study the relationship with UV changes, the partial accumulated ozone loss columns (AOL) simulated by the ATOLL model for the 1997-2005 period have been used. The partial ozone columns are retrieved in the altitude range $350-650 \mathrm{~K}$ where heterogeneous chemistry processes induce chemical ozone loss due to the presence of PSC at these polar altitude regions as shown in Fig. 6 of Parrondo et al. (2007) for the year 2003.

\subsection{Characterization of ozone loss and UV changes rela- tionship}

In this section, we analyze the relationship between the accumulated ozone loss in the $350-650 \mathrm{~K}$ potential temperature range and the $\mathrm{UV}$ increases in the $50^{\circ} \mathrm{S}-60^{\circ} \mathrm{S}$ latitude band. In order to link the partial column of the accumulated ozone loss (AOL) derived from ATOLL simulations to UVI and TOC changes (Sect. 2.2), we have computed total ozone from the partial ozone column of the model between 350 and $950 \mathrm{~K}$. The ozone climatology of Fortuin et al. (1998) was used to compute the partial ozone columns below $350 \mathrm{~K}$ and above $950 \mathrm{~K}$. However, comparisons with sondes and POAM (Polar Ozone and Aerosols Measurements) III measurements (Bevilacqua et al., 2002) for POC below $350 \mathrm{~K}$ and above $950 \mathrm{~K}$, respectively, revealed biases of this climatology in the Polar Regions. Correction terms were thus applied to the climatology in order to reach a better agreement with the measurements. In addition, a correction term was also computed for the overestimation of ozone by the model between 600 and $950 \mathrm{~K}$ due to initialization problems. Ozonesondes in Antarctic stations (South Pole, McMurdo, Marambio and Dumont d'Urville) and POAM data were used for this correction terms.

The relative UVI and TOC differences due to vortex overpasses and computed from TOMS data for quasi-clear sky conditions are shown in the second and third columns of Table 1a. For comparison, corresponding TOC results for ATOLL are given in the fourth column of the table. For each average value, the $2 \sigma$ standard error is indicated. The fifth column corresponds to a spatial mean number of days of vortex occurrences $\left(\mathrm{VO}_{s p}\right)$.

In order to study the influence of chemical ozone loss on UV increase, the method described in Sect. 2.1 is applied for the partial ozone column simulated by ATOLL in the 350$650 \mathrm{~K}$ range (POC) and the accumulated ozone loss in the same potential temperature range $(\mathrm{AOL})$. The $\mathrm{POC}$ values inside and inner edge of the vortex $\left(\mathrm{POC}_{i}\right)$ and $\mathrm{POC}$ climatology $\left(\mathrm{POC}_{\mathrm{cli}}\right)$ are defined in Eqs. (4) and (5), respectively.

$\operatorname{POC}_{i}(\lambda, \varphi, d)=\operatorname{POC}_{i \_ \text {dyn }}(\lambda, \varphi, d)-\mathrm{AOL}_{i \_ \text {hom }}(\lambda, \varphi, d)-\operatorname{AOL}_{i \_ \text {het }}(\lambda, \varphi, d)$ 
Table 1a. Mean UVI and TOC relative differences of TOMS (columns 1 and 2, respectively) and TOC relative differences of ATOLL (column 3 ) for the $50^{\circ} \mathrm{S}-60^{\circ} \mathrm{S}$ latitude band and the corresponding $2 \sigma$ Standard Error according to classification with maximum admissible reflectivity value for September, October and November. These values were averaged over the 1997-2005 period. The monthly values of the mean spatial vortex occurrences are shown in the last column.

\begin{tabular}{|c|c|c|c|c|}
\hline & \multicolumn{3}{|c|}{ Mean relative values } & \multirow{2}{*}{$\begin{array}{l}\begin{array}{l}\text { Mean } \\
\text { spatial } \\
\text { values }\end{array} \\
\mathrm{VO}_{s p} \\
\text { days }\end{array}$} \\
\hline Month & $\begin{array}{l}\frac{\Delta \mathrm{UVI}}{\mathrm{UVI}} \\
\%\end{array}$ & $\begin{array}{l}\frac{\Delta \mathrm{TOC}_{T}}{\operatorname{TOC}_{T \mathrm{cli}}} \\
\%\end{array}$ & $\begin{array}{l}\frac{\Delta \mathrm{TOC}_{A}}{\mathrm{TOC}_{A \mathrm{cli}}} \\
\%\end{array}$ & \\
\hline September & $24.6 \pm 0.6$ & $-25.6 \pm 0.3$ & $-29.9 \pm 0.2$ & $4.7 \pm 0.2$ \\
\hline October & $47.3 \pm 1.0$ & $-29.6 \pm 0.3$ & $-35.5 \pm 0.2$ & $3.8 \pm 0.2$ \\
\hline November & $26.1 \pm 1.5$ & $-16.2 \pm 0.6$ & $-17.6 \pm 0.5$ & $1.5 \pm 0.1$ \\
\hline
\end{tabular}

$\mathrm{POC}_{\text {cli }}(\lambda, d)=\mathrm{POC}_{\text {dyn_cli }}(\lambda, d)-\mathrm{AOL}_{\text {hom_cli }}(\lambda, d)-\mathrm{AOL}_{\text {het_cli }}(\lambda, d)$

Where $\mathrm{POC}_{i \_ \text {dyn }}$ corresponds to the partial ozone column affected only by transport processes at latitude $\lambda$, longitude $\varphi$ and day $d$. The $\operatorname{AOL}_{i \text { hom }}(\lambda, \varphi, d)$ and $\operatorname{AOL}_{i \text { het }}(\lambda, \varphi, d)$ correspond to the ozone loss at the latitude $\lambda$, longitude $\varphi$ and day $d$. The former one is due to homogeneous chemistry only while the latter one is due to heterogeneous chemistry only. The different terms in Eq. (5) represent the same parameters of Eq. (4) but for the climatology over the 1997-2005 period. The monthly climatology determined for situations outside the vortex at each $1^{\circ} \times 1^{\circ}$.

The partial ozone column differences were computed as described in Eq. (6):

$$
\begin{aligned}
& \frac{\Delta \mathrm{POC}(\lambda, \varphi, d)}{\operatorname{POC}_{\mathrm{cli}}(\lambda, d)}=\frac{\Delta \operatorname{POC}_{\mathrm{dyn}}(\lambda, \varphi, d)}{\operatorname{POC}_{\mathrm{cli}}(\lambda, d)}- \\
& \frac{\Delta \mathrm{AOL}_{\mathrm{hom}}(\lambda, \varphi, d)}{\operatorname{POC}_{\mathrm{cli}}(\lambda, d)}-\frac{\Delta \mathrm{AOL}_{\mathrm{het}}(\lambda, \varphi, d)}{\operatorname{POC}_{\mathrm{cli}}(\lambda, d)}
\end{aligned}
$$

Where for each term $X$ of the right hand side of Eq. (6)

$$
\frac{\Delta X(\lambda, \varphi, d)}{\operatorname{POC}_{\mathrm{cli}}(\lambda, d)}=\frac{X_{i}(\lambda, \varphi, d)-X_{\mathrm{cli}}(\lambda, d)}{\operatorname{POC}_{\mathrm{cli}}(\lambda, d)}
$$

The climatological values of $\mathrm{POC}_{\mathrm{dyn} \_c l i}, \mathrm{AOL}_{\text {hom_cli }}$ and $\mathrm{AOL}_{\text {het_cli }}$ are calculated as in Sect. 2.1. Table $1 \mathrm{~b}$ shows the mean relative values of these parameters for SeptemberNovember of the $1997-2005$ period in the $50^{\circ} \mathrm{S}-60^{\circ} \mathrm{S}$ latitude region. Table 1a shows that the model presents mean TOC decrease values larger than TOMS ones in September and October. This is due to an overestimation of the ozone depletion by the model for TOC values inside the vortex (10\% in average). The differences of the mean TOC decreases between ATOLL and TOMS are larger in October but they are generally smaller than $6 \%$ according to the table. The correlation coefficient between ATOLL and TOMS
Table 1b. Same as Table 1a for the mean relative value of the partial ozone column difference between 350 and $650 \mathrm{~K}$ (column 1) of ATOLL and the corresponding $2 \sigma$ Standard Error. The partial ozone column due to dynamics (column 2) and the partial ozone loss column due to homogeneous chemistry (column 3) and heterogeneous chemistry (column 4), according to Eq. (7), are also shown.

\begin{tabular}{lllll}
\hline \multicolumn{5}{c}{ Mean relative values } \\
\hline Month & $\frac{\Delta \mathrm{POC}}{\mathrm{POC}_{\mathrm{cli}}}$ & $\frac{\Delta \mathrm{POC}_{\mathrm{dyn}}}{\mathrm{POC}_{\mathrm{cli}}}$ & $\frac{\Delta \mathrm{AOL}_{\mathrm{hom}}}{\mathrm{POC}_{\mathrm{cli}}}$ & $\frac{\Delta \mathrm{AOL}_{\mathrm{het}}}{\mathrm{POC}_{\mathrm{cli}}}$ \\
& $\%$ & $\%$ & & $\%$ \\
\hline September & $-45.2 \pm 0.3$ & $1.6 \pm 0.3$ & $3.7 \pm 0.1$ & $43.6 \pm 0.3$ \\
October & $-56.7 \pm 0.3$ & $5.5 \pm 0.4$ & $4.1 \pm 0.1$ & $56.9 \pm 0.4$ \\
November & $-39.1 \pm 0.8$ & $15.0 \pm 1.0$ & $4.0 \pm 0.1$ & $47.8 \pm 1.1$ \\
\hline
\end{tabular}

ozone differences is 0.74 in September, 0.68 in October and 0.78 in November.

The largest UV and ozone changes due to vortex occurrences are found in October. Over the whole 1997-2005 period, vortex occurrences induce a mean UVI increase of $47.3 \%$ as compared to climatological value. This UVI increase is associated to a mean total ozone decrease of $29.6 \%$ computed from TOMS and 35.5\% from ATOLL. It corresponds to an average ozone decrease of $56.7 \%$ in the 350 $650 \mathrm{~K}$ altitude range. The average values of UVI increase for both other months are smaller. September presents a mean UVI increase similar in absolute value to the average TOC difference by the fact that the maximum reflectivity value for quasi clear sky conditions in September is rather large, 27.5\% (see Fig. 1), due to a poorer statistical sampling of clear sky conditions during this month, together with a higher dispersion of the UV index values as a function of reflectivity in the lower reflectivity values range (see Fig. 1).

As expected, polar air masses linked to vortex occurrences are mostly influenced by the ozone loss due to heterogeneous chemistry $\left(\mathrm{AOL}_{\text {het }}\right)$ as shown in Table $1 \mathrm{~b}$. In September, this difference in ozone loss amounts to about $45 \%$ of the partial ozone column climatological value. October shows a mean $\mathrm{AOL}_{\text {het }}$ difference of $56.7 \%$. In November, the values are smaller than in October. The mean differences of ozone loss due to homogeneous processes are generally positive and of the order of $4 \%$. The effect of dynamical processes is relatively weak in the spring period as compared to that of heterogeneous processes. The effect of homogeneous chemistry is comparable in the different months while the effect of dynamical processes is increasing with time during the analyzed period. 

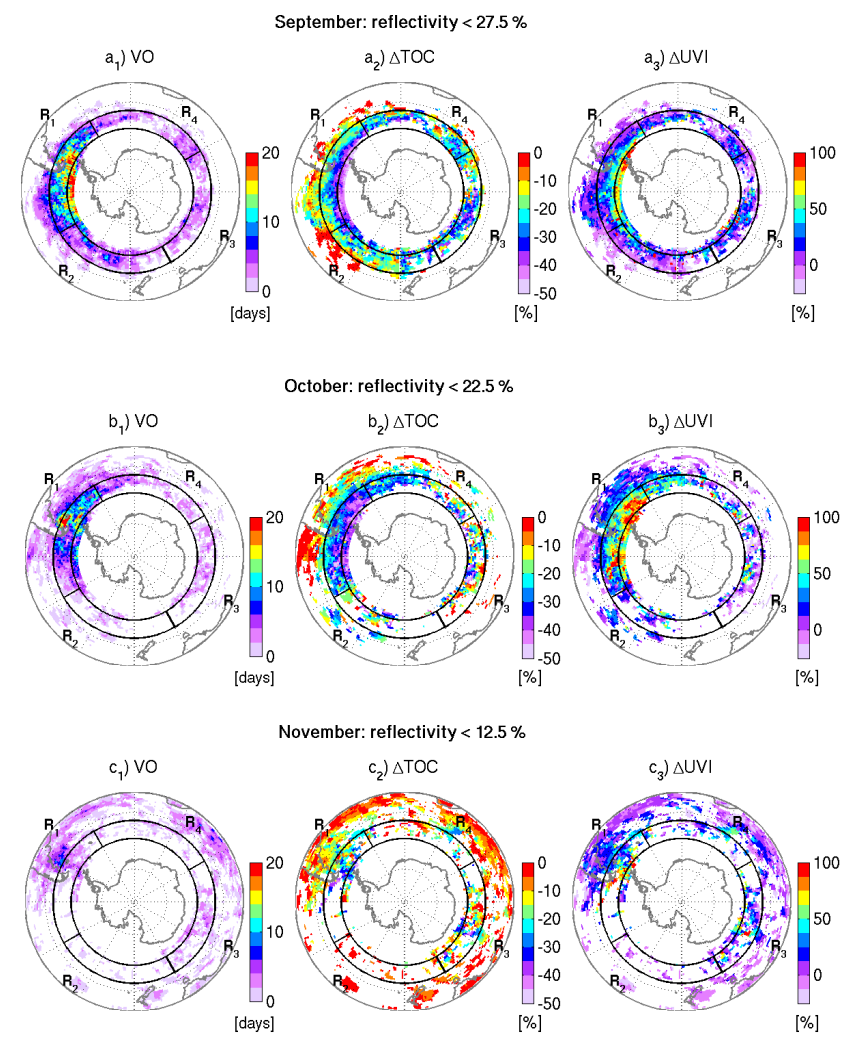

Fig. 6. (1) Number of vortex occurrences (VO), (2) TOC differences and (3) UVI changes for September (a), October (b) and November (c) months over the 1997-2005 period. Latitude band $50^{\circ} \mathrm{S}-60^{\circ} \mathrm{S}$ is emphasized. Only data corresponding to reflectivity values lower than $27.5 \%, 22.5 \%$ and $12.5 \%$, respectively, are considered.

\section{Combined effect of cloud cover and vortex occur- rences on $U V$ radiation}

According to ATOLL simulations and vortex classification, some regions were shown to be more affected by vortex occurrences (Fig. 4). However, the cloud cover can mask the effect of vortex occurrences with low ozone values on the evolution of the UV radiation reaching the surface. In order to determine the regions that are the most vulnerable to potential UV enhancement in a cloud cover decrease scenario during the period of high stratospheric effective chlorine level, the previous analysis was performed considering a larger threshold for the reflectivity values, allowing thus a larger number of vortex occurrences to be selected. This threshold corresponds to mean positive UV changes in Fig. 1: $40 \%$ for September and October, and 25\% for November. The analysis was performed for four regions determined in the $50^{\circ} \mathrm{S}-60^{\circ} \mathrm{S}$ latitude band. It should be noted that according to regional models run under the IPCC scenarios (IPCC, 2007), the stormtracks should move South, increasing precipitation in southern Patagonia and Tierra del Fuego. The same IPCC report presents results that show a decrease in precipitation (so it is expected a decrease in cloud cover) in the middle western part of Patagonia. Cloud-cover changes in the future will be different depending on the region. Our study is thus only speculative. The objective was to identify the most vulnerable regions in case the cloud cover would decrease in the southern mid-latitude regions prior to the recovery of the ozone layer. Figure 6 shows the total number of vortex occurrences over the 1997-2005 period (left panels) for the previously defined clear sky conditions: reflectivity lower than $27.5 \%$ for September, $22.5 \%$ for October and $12.5 \%$ for November. The middle and right panels correspond to mean TOC differences and UVI changes, respectively, from TOMS measurements. The 4 regions correspond to the following longitude bands (1) $\left[30^{\circ} \mathrm{W}-120^{\circ} \mathrm{W}\right]$; (2) $\left[120^{\circ} \mathrm{W}-150^{\circ} \mathrm{E}\right],(3)\left[150^{\circ} \mathrm{E}-60^{\circ} \mathrm{E}\right]$ and $(4)\left[60^{\circ} \mathrm{E}-30^{\circ} \mathrm{W}\right]$. They are shown in Fig. 6. We observe that in September and October the number of vortex occurrences with quasiclear sky conditions over the studied period is the largest in region 1 , where it varies from 5 to 20 days over the $9 y$ close to the southern part of South America. In region 1, the ozone decrease varies from $20 \%$ to $50 \%$ in both months but it presents the largest values in October. The corresponding UVI increases range from $25 \%$ to $100 \%$. The other regions present negligible values compared to region 1 in both months. November is characterized by weaker number vortex occurrences in the different regions. Slightly higher influence of vortex overpasses is observed in region 1 and 3 during this month $(<6$ days). In these regions, the average TOC decrease and UVI increase reach $35 \%$ and $100 \%$, respectively, in some elementary grid area $\left(1^{\circ} \times 1^{\circ}\right)$.

Table 2 shows for September, October and November the average number of vortex occurrences in the 4 regions of the $50^{\circ} \mathrm{S}-60^{\circ} \mathrm{S}$ latitude band, together with the mean value for the whole latitude band. The TOC differences and the corresponding $2 \sigma$ standard error for the new quasi-clear sky conditions are also presented. The vortex occurrences are shown for quasi-clear sky conditions $\left(\mathrm{VO}_{1}: 27.5 \%\right.$ for September, $22.5 \%$ for October and $12.5 \%$ for November, see Fig. 6) and for the new quasi-clear sky scenario $\left(\mathrm{VO}_{2}: 40 \%\right.$ for September and October and 25\% for November). The absolute difference between mean relative TOC decreases between relaxed and non relaxed quasi-clear sky conditions is lower than $\pm 2 \%$ for most regions, except region 2 that presents a larger value $( \pm 4 \%)$ in the October-November period. As seen in previous results, October is the month characterized by the largest ozone decreases in most regions. Region 1 (R1) corresponding to the populated areas of South America is the most affected by vortex occurrences in a possible cloudiness decrease scenario (situations with reflectivity $<40 \%$ ) with a mean $\mathrm{VO}_{2}$ value of around 24 days in September and October and 5 days in November over the $9 \mathrm{y}$. In addition, this region presents the largest mean TOC decrease values compared to the other regions in September and October. A mean TOC decrease of about $30 \%$ is 
Table 2. Spatial mean vortex occurrences are represented for September, October and November for the 4 regions of the $50^{\circ} \mathrm{S}-60^{\circ} \mathrm{S}$ latitude band and for the whole latitude band (regions 1 to 4 ). The vortex occurrences are shown for quasi-clear sky conditions $\left(\mathrm{VO}_{1}: 27.5 \%\right.$ for September, $22.5 \%$ for October and $12.5 \%$ for November) and for the new quasi-clear sky scenario $\left(\mathrm{VO}_{2}: 40 \%\right.$ for September and October and $25 \%$ for November). The TOC differences and the corresponding $2 \sigma$ Standard Error for the new quasi-clear sky conditions are also represented.

\begin{tabular}{|c|c|c|c|c|c|c|c|c|c|}
\hline \multirow[b]{2}{*}{$R$} & \multicolumn{3}{|c|}{ September } & \multicolumn{3}{|c|}{ October } & \multicolumn{3}{|c|}{ November } \\
\hline & $\begin{array}{l}\mathrm{VO}_{1} \\
\text { days }\end{array}$ & $\begin{array}{l}\mathrm{VO}_{2} \\
\text { days }\end{array}$ & $\begin{array}{l}\frac{\Delta \mathrm{TOC}}{\mathrm{TOC} \mathrm{C}_{\mathrm{cli}}} \\
\%\end{array}$ & $\begin{array}{l}\mathrm{VO}_{1} \\
\text { days }\end{array}$ & $\begin{array}{l}\mathrm{VO}_{2} \\
\text { days }\end{array}$ & $\begin{array}{l}\frac{\Delta \mathrm{TOC}}{\mathrm{TOC}} \\
\%\end{array}$ & $\begin{array}{l}\mathrm{VO}_{1} \\
\text { days }\end{array}$ & $\begin{array}{l}\mathrm{VO}_{2} \\
\text { days }\end{array}$ & $\begin{array}{l}\frac{\Delta \mathrm{TOC}}{\mathrm{TOC}} \\
\%\end{array}$ \\
\hline 1 & 9.3 & 25.7 & $-31.9 \pm 0.3$ & 6.4 & 23.6 & $-36.8 \pm 0.2$ & 1.8 & 5.1 & $-20.9 \pm 0.4$ \\
\hline 2 & 3.3 & 8.9 & $-25.9 \pm 0.3$ & 1.3 & 3.0 & $-30.9 \pm 0.7$ & 1.1 & 1.7 & $-7.4 \pm 0.6$ \\
\hline 3 & 2.1 & 4.8 & $-27.5 \pm 0.4$ & 1.6 & 5.8 & $-24.0 \pm 0.4$ & 1.5 & 5.7 & $-16.2 \pm 0.3$ \\
\hline 4 & 2.3 & 6.1 & $-27.3 \pm 0.3$ & 2.3 & 10.3 & $-30.6 \pm 0.5$ & 1.2 & 4.1 & $-19.8 \pm 0.4$ \\
\hline 1 to 4 & 4.7 & 11.9 & $-28.2 \pm 0.2$ & 3.8 & 11.5 & $-30.7 \pm 0.3$ & 1.5 & 4.4 & $-16.6 \pm 0.3$ \\
\hline
\end{tabular}

computed for these months, corresponding to a mean UV increase of $35 \%$, according to Fig. 5. In such a scenario, the populated regions of South America would see the largest increase in the number of vortex occurrences in September and October, the months when the UV increase is largest. The other regions ( 2 to 4 ) show substantially lower increase in the number of vortex occurrences, with generally lower average ozone decreases. However, the relative increase in the number of vortex occurrences defined as $\mathrm{VOAF}=\mathrm{VO}_{2} / \mathrm{VO}_{1}$, is almost similar in all 4 regions. Region 4 shows a larger VOAF in October (4.5) with a large ozone decrease (30.6\%) but with a smaller number of occurrences as compared to region 1 (10 to 24 days, respectively over the $9 y$ ). In November, lower TOC decreases and number of vortex occurrences are observed in all 4 regions as compared to both other months. Region 2 is the least affected area due to weak ozone decrease $(7 \%)$ and a weak increase in the number of vortex occurrence (1.1 to 1.7 days). Regions 1,3 and 4 present similar and moderate TOC decrease values (16 to $21 \%$ ) and weak vortex occurrences ( 4 to 5 days over the $9 \mathrm{y}$ ).

\section{Summary and conclusions}

UV index together with total ozone and reflectivity data from TOMS were used in order to characterize the UV enhancement in sub-polar regions associated with intrusion of polar ozone depleted air masses in the 1997-2005 period. The frequency of vortex occurrences was found to be larger than $90 \%$ in regions polewards of $70^{\circ} \mathrm{S}$ except in 2002 due to the major warming at the end of September. Northward of $60^{\circ} \mathrm{S}$, vortex occurrence frequencies showed large interannual variability from one year to the next. In the studied period, a longitudinal asymmetry of vortex occurrences over the subpolar regions was observed, presenting the highest frequency values in the $\left[90^{\circ} \mathrm{W}-90^{\circ} \mathrm{E}\right]$ sector for the $40^{\circ} \mathrm{S}-60^{\circ} \mathrm{S}$ latitude band. In these regions, vortex occurrences are mostly observed during the September-November period. This is explained by the higher planetary wave activity during this period, moving the vortex to subpolar regions. The study was thus focused in the September-November period in the $50^{\circ} \mathrm{S}-60^{\circ} \mathrm{S}$ latitude band to highlight the influence of vortex occurrences on UV and total ozone over these regions. The results corresponding to the $40^{\circ} \mathrm{S}-50^{\circ} \mathrm{S}$ latitude band was also analyzed for comparison.

Total ozone differences and UVI changes were evaluated by comparing the situations inside the vortex with climatological values corresponding to situations outside the vortex. In the case of UVI and for situations inside the vortex, a relaxed condition was determined for clear sky conditions by evaluating the UV changes as a function of reflectivity. In such conditions, UVI increases larger than $80 \%$ for TOC decreases larger than $45 \%$ were observed in September, October and November in the $50^{\circ} \mathrm{S}-60^{\circ} \mathrm{S}$ latitude band and September and October in the $40^{\circ} \mathrm{S}-50^{\circ} \mathrm{S}$ one. As expected, the $50^{\circ} \mathrm{S}-60^{\circ} \mathrm{S}$ latitude band presents the highest UVI increases. November shows the lowest UVI increases and TOC decreases in both latitude bands. The average value of the number of vortex occurrences combined with quasiclear sky conditions over the $50^{\circ} \mathrm{S}-60^{\circ} \mathrm{S}$ latitude band is quite small, $\sim 5$ days for September, $\sim 4$ days for October and 1.5 days for November. But values of vortex occurrences had reached 20 days on September and October close to the south of America continent.

A high resolution $\left(1^{\circ} \times 1^{\circ}\right)$ transport model coupled to an ozone loss parameterization scheme (called ATOLL) was used in order to characterize the evolution of the ozone loss in the Southern Hemisphere between 1997 and 2005 for the $50^{\circ} \mathrm{S}-60^{\circ} \mathrm{S}$ latitude band. The simulations showed correct agreement with sondes and SAGE II measurements in the $350-650 \mathrm{~K}$ potential temperature range. October is the period with maximum average increase of UVI, ozone loss and decrease of total columns for the $50^{\circ} \mathrm{S}-60^{\circ} \mathrm{S}$ latitude band. As expected, the accumulated ozone loss 
(AOL) due to heterogeneous reactions represents the highest contribution to ozone decrease in the $350-650 \mathrm{~K}$ altitude range $\left(\mathrm{AOL}_{\mathrm{het}} \cong 57 \%\right)$. These mean values of UVI and TOC differences are mostly weighed by values in region 1 (R1 South America, see upper panels of Fig. 6) due to rather low cloud cover percentage in this region.

In order to determine the most vulnerable regions to potential UV enhancements linked to vortex occurrences in a cloudiness decrease scenario, the number of vortex occurrences and total ozone difference from TOMS measurements were computed for situations with new relaxed reflectivity conditions. The vortex occurrences with a new relaxed reflectivity threshold of $40 \%$ for September and October, and 25\% for November, corresponding to positive UV changes, were considered as an extreme scenario for cloud cover decrease. In such conditions, October still shows the highest ozone decrease values in the considered regions. The region close to South America stands out as the most sensitive region due to the combined effect of large number of vortex occurrences, rather low cloud cover and large ozone decrease. This is the case for the three months considered in this study. In this region, the mean number of vortex occurrences over the 1997-2005 period would increase from $\sim 6$ days in quasi clear sky conditions to $\sim 24$ days with a corresponding mean ozone decrease of $\sim 37 \%$ in October. Such ozone decrease would induce a mean UV enhancement of $50 \%$. The regions 2 to 4 show a little lower or comparable values of TOC decreases and vortex occurrences compared to the mean values considering the whole $50^{\circ} \mathrm{S}-60^{\circ} \mathrm{S}$ latitude band in September and October. As in the whole subpolar latitude regions, the dilution of the polar vortex in November and December induces an enhancement of UV radiation in these regions as compared to pre-ozone hole conditions, but they are statistically much less affected by large sudden UV increase. Note that our results represent a simple case of cloudiness decrease in regions in the Southern Hemisphere. More realistic scenarios could be taken into account for each particular region.

Due to the large correlation between the UVB range with the erythemal irradiance (or UVI) and other biological irradiances sensible to this solar spectral range (ADN and eye damage, carcinogenesis, phytoplankton, etc.) (UNEP, 2007), the present results could be extended to the analysis of these biological effects. Since 4 September 2007, corrected data set for ozone and reflectivity calculated by Version 8 are available from TOMS webpage (ftp://toms.gsfc. nasa.gov/pub/eptoms/data/ozone/). The two V8 were compared for ozone and reflectivity distinguishing the data considered inside and outside (climatology) the vortex following the definition given in Sect. 2.1 of this paper. Only the $50^{\circ} \mathrm{S}-60^{\circ} \mathrm{S}$ latitude band was considered. The differences in total ozone value are rather small between both versions. Monthly average ozone values in the new version are larger by 4 to $5 \mathrm{DU}$ for both inside and outside vortex situations in the 3 months considered in this study, while the correlation coefficient are very close to 1 . The difference between both versions is larger in the reflectivity data. The new V8 reflectivity presents a monthly average underestimation of 0 to $3 \%$ reflectivity value for both situations in the analyzed months. The correlation coefficient is 0.92 for September, 0.96 for October and 0.85 for November for inside situations. Weaker values were found for the outside situations (reflectivity $<7.5 \%$ ), 0.67 for September, 0.78 for October and 0.69 for November. We estimated that this new reflectivity data could have some impact on the UV analysis. A new study using the methodology described in this paper will be performed when a coherent ozone/UV/reflectivity data set comes out and a comparison will be made with the results obtained in this work.

Acknowledgements. The authors thank the TOMS team for providing the ozone, UV and reflectivity data and ECMWF for meteorological data. RDP acknowledge the support provided by the Argentina Agency for the Promotion of Science and Technology and CONICET. This work was performed within the ORACLE-O3 France project funded by the Agence Nationale pour La Recherche. The authors also thank the two anonymous reviewers for their useful and constructive comments.

Edited by: M. Dameris

\section{References}

Ajtić, J., Connor, B. J., Lawrence, B. N., Bodeker, G. E., Hoppel, K. W., Rosenfield, J. E., and Heuff, D. N.: Dilution of the Antarctic ozone hole into southern midlatitudes, 1998-2000. J. Geophys. Res., 109, D17107, doi:10.1029/2003JD004500, 2004.

Allen, D., Bevilacqua, R., Nedoluha, G., Randall, C., and Manney, G.: Unusual stratospheric transport and mixing during 2002 Antarctic winter, Geophys. Res. Lett., 30, 1599, doi:10.1029/2003GL017117, 2003.

Bevilacqua, R. M., Fromm, M. D., Alfred, J. M., Hornstein, J. S., Nedoluha, G. E., Hoppel, K. W., Lumpe, J. D., Randall, C. E., Shettle, E. P., Browell, E. V., Butler, C., Dörnbrack, A., and Strawa, A. W.: Observations and analysis of polar stratospheric clouds detected by POAM III during the 1999/2000 Northern Hemisphere winter, J. Geophys. Res., 107(D20), 8281, doi:10.1029/2001JD000477, 2002.

Bodeker, G. E., Struthers, H., and Connor, B. J.: Dynamical containment of Antarctic ozone depletion, Geophys. Res. Lett., 29, 1098, doi:10.1029/2001GL014206, 2002.

Casiccia, C., Kirchhoff, V. W. J. H., and Torres, A.: Simultaneous measurements of ozone and ultraviolet radiation: Spring 2000, Punta Arenas, Chili, Atmos. Environ., 37(3), 383-389, 2003.

Cede, A., Luccini, E., Nuñez, L., Piacentini, R. D., and Blumthaler, M.: Monitoring of erythemal irradiance in the Argentine Ultraviolet Network, J. Geophys. Res., 107(D13), 4165, doi:10.1029/2001JD001206, 2002.

Compagnucci, R. H., Salles, M. A., and Canziani, P. O.: The spatial and temporal behaviour of the lower stratospheric temperature over the Southern Hemisphere: The MSU view, Part I: 
Methodology and temporal behaviour, Int. J. Climatol., 21, 1215-1228, 2001.

Eck, T. F., Barthia, P. K., Wang, P. H., and Stowe, L. L.: Reflectivity on Earth's surface and clouds in ultraviolet from satellite from satellite observations, J. Geophys. Res., 92, 4287-4296, 1987.

Fortuin, J. P. F. and Kelder, H.: An ozone climatology based on ozonesonde and satellite measurements, J. Geophys. Res., 103(D24), 31 709-31 734, 1998.

Gille, J. C. and Russell III, J. M.: The Limb Infrared Monitor of the Stratosphere: Experiment Description, Performance, and Results, J. Geophys. Res., 89(D4), 5125-5140, 1984.

Godin, S., Bergeret, V., Bekki, S., David, C., and Mégie, G.: Study of the interannual ozone loss and permeability of the Antarctic polar vortex from aerosols and ozone lidar measurements in Dumont d'Urville (66.4 $\left.{ }^{\circ} \mathrm{S}, 140^{\circ} \mathrm{E}\right)$, J. Geophys. Res., 106(D1), 1311-1330, 2001.

Hadjinicolaou, P. and Pyle, J. A.: The Impact of Arctic Ozone Depletion on Northern Middle Latitudes: Interannual Variability and Dynamical Control, J. Atmos. Chem., 47(1), 25-43, 2004.

Hanson, D. and Mauersberger, K.: Laboratory Studies of the Nitric Acid Trihydrate: Implications for the South Polar Stratosphere, Geophys. Res. Lett., 15, 855-858, 1988.

Hauchecorne, A., Godin, S., Marchand, M., Heese, B., and Souprayen, C.: Estimation of the Transport of Chemical Constituents from the Polar Vortex to Middle Latitudes in the Lower Stratosphere using the High-Resolution Advection Model MIMOSA and Effective Diffusivity, J. Geophys. Res., 107(D20), 8289, doi:10.1029/2001JD000491, 2002.

Herman, J. R. and Celarier, E. A.: Earth surface reflectivity climatology at 340-380 nm from TOMS data, J. Geophys. Res., 102, 28 003-28 011, 1997.

Herman, J. R., Krotkov, N., Celarier, E., Larko, D., and Labow, G.: The distribution of UV radiation at the Earth's surface from TOMS measured UV-backscattered radiances. J. Geophys. Res., 104, 12 059-12 076, 1999.

Hoppel, K., Bevilacqua, R., Allen, D., Nedoluha, G., and Randall, C.: POAM III observations of the anomalous 2002 Antarctic ozone hole, Geophys. Res. Lett., 30, 1394, doi:10.1029/2003GL016899, 2003.

Huth, R. and Canziani, P. O.: Classification of hemispheric monthly mean stratospheric potential vorticity fields, Ann. Geophys., 21, 805-817, 2003,

http://www.ann-geophys.net/21/805/2003/.

IPCC (Intergovernmental Panel on Climate Change), IPCC Fourth Assessment Report: Climate Change 2007, Geneva, Switzerland, 2007.

Kirchhoff, V. W. J. H., Sahai, Y., Casiccia S., C. A. R., Zamorano B., S. F., and Valderrama V., V.: Observations of the 1995 ozone hole over Punta Arenas, Chile, J. Geophys. Res., 102, 16109 $16120,1997$.

Kondragunta, S., Flynn, L. E., Neuendorffer, A., Miller, A. J., Long, C., Nagatani, R., Zhou, S., Beck, T., Beach, E., McPeters, R., Stolarski, R., Bhartia, P. K., DeLand, M. T., and Huang, L.-K.: Vertical Structure of the Anomalous Antarctic Ozone Hole, J. Atmos. Sci., 62(3), 801-811, 2005.

Krotkov, N., Herman, J., Bhartia, P. K., Seftor, C., Arola, A., Kaurola, J., Kalliskota, S., Taalas, P., and Geogdzhaev, I. V.: Version 2 total ozone mapping spectrometer ultraviolet algorithm: problems and enhancements, Opt. Eng., 41(12), 3028-3039, 2002.
Labow, G. J., McPeters, R. D., and Bhartia, P. K.: A Comparison of TOMS and SBUV Version 8 Total Column Ozone Data with Data from Groundstations, Proceedings of the Quadrennial Ozone Symposium, Kos, Greece, 1-8 June 2004, 123-124, 2004.

Luccini, E., Cede, A., Piacentini, R., Villanueva, C., and Canziani, P.: Ultraviolet climatology over Argentina, J. Geophys. Res., 111, D17312, doi:10.1029/2005JD006580, 2006.

Madronich, S., McKenzie, R. L., Björn, L. O., and Caldwell, M. M.: Changes in biologically active ultraviolet radiation reaching the Earth's surface, J. Photoch. Photobio. B., 46, 5-19, 1998.

Malanca, F. E., Canziani, P. O., and Argüello, G. A.: Trends evolution of ozone change between 1980 and 2000 at mid-latitudes over the Southern Hemisphere: Decadal differences in trends, J. Geophys. Res., 110, D05102, doi:10.1029/2004JD004977, 2005.

Marchand, M., Bekki, S., Pazmino, A., Lefèvre, F., GodinBeekmann, S., and Hauchecorne, A.: Model Simulations of the Impact of the 2002 Antarctic Ozone Hole on the Midlatitudes, J. Atmos. Sci., 62(3), 871-884, 2005.

Mauldin III, L. E., Zaun, N. H., McCormick, M. P., Guy, J. H., and Vaughn, W. R.: Stratospheric Aerosol and Gas Experiment II Instrument: A Functional Description, Opt. Eng., 24(2), 307312, 1985.

McIntyre, M. and Palmer, T.: The "surf-zone" in the stratosphere, J. Atmos. Terr. Phys., 46, 825-849, 1984.

McLinden, C. A., Olsen, S. C., Hannegan, B., Wild, O., Prather, M. J., and Sundet, J.: Stratospheric ozone in 3-D models: A simple chemistry and the cross-tropopause flux, J. Geophys. Res., 105(D11), 14 653-14 665, 2000.

McPeters, R. D., Bhartia, P. K., Krueger, A. J., Herman, J. R., Wellemeyer, Ch. G., Seftor, C. J., Jaross, G., Torres, O., Moy, L., Labow, G., Byerly, W., Taylor, S. L., Swissler, T., and Cebula, R. P.: Earth Probe Total Ozone Mapping Spectrometer (TOMS) Data Products User's Guide, Nasa Technical Publication, Goddard Space Flight Center/NASA, Greenbelt, MD, p. 64, 1998.

Micheletti, M. I., Piacentini, R. D., and Madronich, S.: Sensitivity of biologically active UV radiation to stratospheric ozone changes: effects of action spectrum shape and wavelengths ranges, Photochem. Photobiol., 78(5), 456-461, 2003.

Moustaoui, M., Teitelbaum, H., and Valero, F. P. J.: Vertical Displacements Induced by Quasi-Stationary Waves in the Southern Hemisphere Stratosphere during Spring, Mon. Weather Rev., 131, 2279-2289, 2003.

Nash, E. R., Newman, P. A., Rosenfield, J. E., and Schoeberl, M. E.: An objective determination of the polar vortex using Ertel's potential vorticity, J. Geophys. Res., 101, 9471-9478, 1996.

Newman, P. A., Nash, E. N., Kawa, S. R., Montzka, S. A., and Schauffler, S. M.: When will the Antarctic ozone hole recover?, Geophys. Res. Lett., 33, L12814, doi:10.1029/2005GL25232, 2006.

Parrondo, M. C., Yela, M., Gil, M., von der Gathen, P., and Ochoa, H.: Mid-winter lower stratosphere temperatures in the Antarctic vortex: comparison between observations and ECMWF and NCEP operational models, Atmos. Chem. Phys., 7, 435-441, 2007 , http://www.atmos-chem-phys.net/7/435/2007/.

Pazmiño A. F., Godin-Beekmann, S., Ginzburg, M., Bekki, S., Hauchecorne, A., Piacentini, R., and Quel, E.: Impact of Antarctic polar vortex occurrences on total ozone and UVB radiation at southern Argentinean and Antarctic stations 
during 1997-2003 period, J. Geophys. Res., 110, D03103, doi:10.1029/2004JD005304, 2005.

Pérez, A., Crino, E., Aguirre de Cárcer, I., and Jacque, F.: Lowozone events and three-dimensional transport at midlatitudes of South America during springs of 1996 and 1997, J. Geophys. Res., 105(D4), 4553-4561, 2000.

Randall, C. E., Manney, G. L., Allen, D. R., Bevilacqua, R. M., Hornstein, J., Trepte, C., Lahoz, W., Ajtic, J., and Bodeker, G.: Reconstruction and Simulations of Stratospheric Ozone Distributions during the 2002 Austral Winter, J. Atmos. Sci., 62, 748764, 2005.

Scaife, A. A., Jackson, D. R., Swinbank, R., Butchart, N., Thoraton, H. E., Keil, M., and Henderson, L.: Stratospheric vacillations and the major warming over Antarctica in 2002, J. Atmos. Sci., 62, 629-639, 2005.

Shine, K.: The middle atmosphere in the absence of dynamical heat flux, Q. J. R. Meteor. Soc., 113, 603-633, 1987.

Tripathi, O. P., Godin-Beekmann, S., Lefèvre, F., Marchand, M., Pazmiño, A., Hauchecorne, A., Goutail, F., Schlager, H., Volk, C. M., Johnson, B., König-Langlo, G., Balestri, S., Stroh, F., Bui, T. P., Jost, H. J., Deshler, T., and von der Gathen, P.: High resolution simulation of recent Artic and Antarctic stratospheric chemical ozone loss compared to observations, J. Atmos. Chem., 55(3), 205-226, doi:10.1007/s10874-006-9028-8, 2006.
UNEP (United Nations Environment Programme), Environmental effects of ozone depletion: 1998 Assessment, UNEP, 205 pp., 1998.

UNEP (United Nations Environment Programme), Environmental effects of ozone depletion and its interaction with climate change: 2006 Assessment, UNEP, 2007.

Wang, P., Li, Z., Cihlar, J., Wardle, D. I., and Kerr, J.: Validation of an UV inversion algorithm using satellite and surface measurements, J. Geophys. Res., 105(D4), 5037-5048, 2000.

WHO (World Health Organization), Global solar UV index: A practical guide, WHO/SDE/OEH, 2, Geneva, Switzerland, 2002.

WMO (World Meteorological Organization), Scientific Assessment of Ozone Depletion: 2002, Global Ozone Research and Monitoring Project-Report No. 47, Geneva, Switzerland, 2003.

WMO (World Meteorological Organization), An Overview of the 2005 Antarctic Ozone Hole, Global Ozone Research and Monitoring Project-Report No. 49, Geneva, Switzerland, 2006.

WMO (World Meteorological Organization) Scientific Ozone Assessment of Ozone Depletion: 2006, Global Ozone Research and Monitoring Project-Report No. 50, Geneva, Switzerland, 2007.

Zwally, M. J., Comiso, J. C., Parkinson, C. L., and Cavalieri, D. J.: Variability of Antarctic sea ice 1979-1998, J. Geophys. Res., 107(C5), 3041, doi:10.1029/2000JC000733, 2002. 